\title{
A construção de um LARR: contações sobre a criação da Liga Acadêmica de Relações Raciais
}

\section{Building LARR: tales about the creation of the Academic League of Race Relations}

\author{
Tainan Silva da Purificação ${ }^{1}$ \\ Henrique Almeida Silva Galrão² (1) \\ Jamille Georges Reis Khouri ${ }^{3}$ (1) \\ Jamile Dantas Nascimento Santos ${ }^{4}$ (1) \\ Marilda Castelar ${ }^{5}$ (1)
}

\footnotetext{
${ }^{1}$ Autora para correspondência. UNIFACS (Salvador). Bahia, Brasil. tatapurificacao@hotmail.com

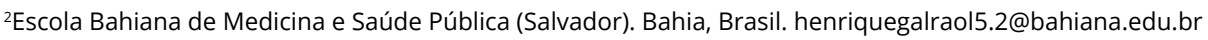
${ }^{3}$ Sociedade de Psicodrama de São Paulo (São Paulo). São Paulo, Brasil. jamillekhouri@hotmail.com 4Universidade de São Paulo (Ribeirão Preto). São Paulo, Brasil. jamiledantas@usp.br ${ }^{5}$ Escola Bahiana de Medicina e Saúde Pública (Salvador). Bahia, Brasil. marildacastelar@bahiana.edu.br
}

RESUMO | O presente artigo tem o objetivo de relatar a experiência de criação da Liga Acadêmica de Relações Raciais na Escola Bahiana de Medicina e Saúde Pública, uma instituição de ensino da cidade de Salvador, Bahia. Trata-se de um estudo de abordagem qualitativa e descritiva, tendo como procedimento o relato de experiência a partir dos registros de reuniões e das reflexões coletivas das autoras/es que vivenciaram os dois primeiros anos do percurso do grupo iniciado em 2016. Como resultado, considera-se a construção da LARR uma experiência que gerou movimentos importantes na instituição de ensino a qual pertence, por visibilizar e ampliar o diálogo entre o corpo docente e discente de um curso de Psicologia, em um contexto cujo, alunas/os, docentes e demais gestores são em sua maioria, brancos. Além disso, em pouco tempo foi possível cumprir os objetivos propostos em seu estatuto.

PALAVRAS-CHAVE: Psicologia. Relações Raciais. Liga Acadêmica.

\begin{abstract}
This article aims to report the experience of creating the Academic League of Race Relations at the BAHIANA - School of Medicine and Public Health, an educational institution in the city of Salvador, Bahia, Brasil. This is a study with a qualitative and descriptive approach, having as procedure reporting experience from the meeting records and the collective reflections of the authors who experienced the first two years of the group's journey, which started in 2016. As a result, the construction of LARR is considered an experience that generated important movements to the educational institution which it belongs, by making visible and amplifying the dialogue between the faculty and the student body of the Psychology course, in a context whose students, professors and other managers are mostly white. Furthermore, in a short time it was possible to achieve the objectives suggested in its statute.
\end{abstract}

KEYWORD: Psychology. Race Relations. Academic League. 


\section{Introdução}

O racismo é uma ideologia que contribui para a manutenção das desigualdades sociais no Brasil, bem como faz parte da construção subjetiva do brasileiro e do sofrimento psíquico vivenciado pela população negra. Em meados do século XX, a Psicologia Social insurge como uma proposta ético-política tanto no ensino, quanto nas áreas de atuação em Psicologia. No Brasil, seu desenvolvimento se deu durante os anos de 1930 e 1950, problematizando temáticas relacionadas as desigualdades sociais e econômicas, bem como denunciando a importância dos estudos sobre as Relações Raciais na área (Santos, Shuckman, \& Martins, 2012).

Entretanto, reconhecendo os empecilhos estruturais, institucionais e individuais provocados pelo racismo, a discussão sobre Psicologia e Relações Raciais (PsiRR) ainda acontece de forma insipiente. Destarte, estratégias de enfrentamento são desenvolvidas e implementadas por estudantes e profissionais implicadas em dar continuidade a um projeto antirracista dentro da Psicologia.

Assim, surge da inquietação de graduandas/os pretas e pretos, da Escola Bahiana de Medicina e Saúde Pública, a Liga Acadêmica de Relações Raciais (LARR). Essa se configura como uma entidade sem fins lucrativos, autônoma e organizada por estudantes do curso de Psicologia que atuam a partir de atividades extracurriculares. Os encontros aconteciam ordinalmente uma vez na semana, através de assembleias, entendendo esse formato como uma forma democrática de socialização da fala. Atendendo esse modelo de organização, o espaço possibilitava um grande fluxo criativo, onde a produção de ideias, projetos e ações eram coletivizadas, acolhendo pontos de vistas convergentes, bem como havendo espaço para críticas e discordâncias. Destaca-se que mesmo com a eleição de lideranças rotativas, não havia a sobreposição hierárquica ou palavras de ordem e disciplina no grupo.

Ainda assim, é possível identificar algumas adversidades no contexto interno da liga, onde a falta de empenho de alguns membros acabavam por sobrecarregar os demais, podendo suscitar diversas interpretações sobre tal postura, desde a densidade da discussão sobre Relações Raciais e seus atravessamentos no corpo daquele(a) integrante, como a falta de investimento e desejo na construção e manutenção do espaço.
As Ligas acadêmicas caracterizam-se pelo objetivo de aprofundar-se em um determinado tema funcionando em um tripé: ensino, pesquisa e extensão (Magalhães, Rechtman \& Barreto, 2015). A LARR tem como objetivo geral desenvolver a responsabilidade e o compromisso social dos membros com as questões Étnico-raciais na atualidade. E tem como objetivos específicos promover a participação em seminários, cursos, congressos e debates que abordem o tema e visa produzir trabalhos científicos para contribuir com a construção do conhecimento cultural e identitário no campo da educação que dialogue com os temas: cultura, raça, cor e etnia.

A LARR possui um estatuto que assegura o funcionamento de acordo com as regras da Escola Bahiana de Medicina e Saúde Pública, sendo composta por 15 alunas/os de Psicologia da mesma instituição que passaram por processo seletivo realizado pelos Membros Fundadores (Presidente, Vice e 3 Psicólogas formadas pela instituição). A LARR iniciou as suas atividades em março de 2016, realizando o total de 13 reuniões (todas as terças-feiras das 14 às 16 horas) dentro da EBMSP e uma sessão aberta para acadêmicas/os da EBMSP e de outras instituições de ensino superior, realizada dentro da instituição.

A Liga realizou estudos de artigos científicos, livros e análise de filmes como metodologia para os encontros. As temáticas estudadas e discutidas foram: O conceito de Racismo, Raça e Etnia; a Construção da Identidade do Afrodescendente; a Luta Antimanicomial e seus reflexos nas Relações Étnicosraciais; o Feminismo Negro atual e as Relações Raciais na Educação.

Diante do exposto, o objetivo do artigo é relatar a experiência da implantação da LARR na EBMSP. Para tal, buscamos relatar a importância e os desafios de criar e sustentar uma Liga acadêmica composta em sua maioria por alunas/os negras/os que tratam o tema das Relações Étnico-raciais em uma instituição privada, cuja comunidade acadêmica é, visivelmente, pertencente em sua maioria ao grupo racial branco. Diante desta realidade, surgiram os seguintes questionamentos: Será que o currículo dos cursos de Psicologia tem gerado debate sobre as Relações Raciais? Como a LARR pode contribuir na formação e preparação para a atuação da psicóloga diante do sofrimento psíquico que pode ser causado pelo racismo existente no Brasil. 
Ao final do primeiro semestre de funcionamento da Liga já foi possível perceber que ainda existia uma grande lacuna no debate das relações Étnicos-raciais neste ambiente acadêmico, mesmo com a existência do grupo de estudos e pesquisa: Psicologia, Diversidade e Saúde, que era o único dentro do curso que trabalhava e estudava questões relacionadas diretamente ao tema da Liga.

Portanto, é fundamental reconhecer tanto a Liga Acadêmica de Relações Raciais como o grupo de estudo e pesquisa enquanto Máquina de Guerra (Hur, 2019) frente a uma produção de saber acadêmico que vem produzindo modos de subjetivação e neocolonização a favor de uma política de controle, silenciamento e apagamento de vidas negras. Através desses espaços possibilitou-se a inserção e o acoIhimentos de estudantes de graduação negros(as), sua potencialização, permitindo a construção de novas narrativas sobre a realidade vivida pelos jovens negros(as) universitários em instituições de ensino privadas, bem como a produção e defesa de uma Psicologia Política.

\section{Relações Raciais e Psicologia}

O Racismo científico no Brasil se configura como a continuidade de um projeto colonial expansionista, iniciado no século XVI na Europa. As teorias racistas, desenvolvidas entre o século XVIII e o XX, eram pautadas nos ideais eugênicos postulados na época, que condenavam a miscigenação enquanto causadoras de desordens morais, bem como causadora de comprometimentos físicos e cognitivos, qual o branco ocupava o topo da hierarquia racial (Nascimento, 2019).

Um dos principais criadores da ciência da Eugenia, foi o naturalista e psicólogo inglês Francis Galton (18221911) que definiu esta ciência como o estudo dos agentes sob o controle social que podem melhorar ou empobrecer as qualidades raciais das futuras gerações, seja física ou mentalmente.

Surge como representante importante das teorias raciais no Brasil: Raimundo Nina Rodrigues, médico baiano de grande prestígio, que estudou os negros e a criminalidade, influenciado pelo italiano Cesare Lombroso, que formulou juntamente com Paul Broca a Teoria de Antropologia Criminal: "defendiam que através de certas características anatômicas podia-se distinguir os perigosos sociais dos criminosos natos" (Pereira, Santos \& Costa, 2001, p.177).

No Brasil, várias foram as tentativas de ações sociais que tinham a ideia da higiene racial como suporte, sobretudo no campo das ciências psicológicas, no início do século XX. Masiero (2005, p.2) ilustra essas ações como: "A Sociedade Eugênica de São Paulo, que funcionou entre 1918 e 1920. A realização de Concursos de Eugenia, entre 1929 e 1932, em São Paulo, quando se procurou selecionar os 'exemplares raciais' brasileiros mais puros". O Estado brasileiro buscava a ordem e o progresso baseado na ciência positiva em que os homens eram guiados pela razão das diferenças naturais entre os grupos/classes da sociedade.

O movimento higienista ganhou muita repercussão dentro da sociedade brasileira indo além da medicina, influenciando os projetos arquitetônicos urbanísticos corroborando para uma exclusão dos negros, mulatos e mestiços que tiveram que morar nas periferias urbanas. "A descrição do negro como lascivo, libidinoso, violento, beberrão, imoral ganha as páginas dos jornais compondo a imagem de alguém em que não se pode confiar" (Santos, 2002, p. 131).

O presente trabalho adotou o conceito de Domingues (2005) sobre a democracia racial. De acordo com o autor, democracia racial "significa um sistema racial desprovido de qualquer barreira legal ou institucional para a igualdade racial, e, em certa medida, um sistema racial desprovido de qualquer manifestação de preconceito ou discriminação" (Domingues, 2005, p. 2). Esta teoria foi adotada como ideologia oficial no Brasil, pois gerava a sensação de alívio entre os brancos em seu conjunto e tirava a responsabilidade do Estado em amparar as/os ex-escravizadas/os e seus descendentes com leis compensatórias por todos os danos causados pelo sistema escravista. Schucman (2010, p.44) corrobora afirmando que "o racismo se desenvolveu de forma muito específica e particular, porque o racismo brasileiro nunca foi legitimado pelo Estado, mas sim foi e ainda é um racismo presente nas práticas sociais e nos discursos".

Em resposta a esse mito, a militância negra buscou se organizar, construindo estratégias de enfrentamento. A Frente Negra Brasileira é um exemplo disso, fundada em setembro de 1931 em São Paulo e entre juIho e novembro de 1932 na Bahia (Barcelar, 2001). Já em 1922, no Rio de Janeiro, Abdias Nascimento funda o Teatro Experimental do Negro (TEN), que visava a 
potencialização dos corpos de negras/os, utilizando enquanto dispositivos as artes, o corpo e a educação (Munanga 2006; Gomes, 2006).

É no bojo dessa história que a psicologia também se aproxima dos estudos sobre as relações raciais no Brasil. Os autores Santos, Schucman e Martins (2017) identificaram três momentos na construção do pensamento psicológico sobre as relações étnico-raciais, sendo eles: Biológico-causal, culturalista e relacional. O primeiro momento, denominado Biológico-causal, pode ser exemplificado com os estudos influenciados pela Eugenia, como já citado anteriormente.

Já os estudos culturalistas sobre raça e nação começaram a se intensificar dentro da Psicologia a partir da década de 1930, período em que o campo da Psicologia Social se consolidava no Brasil. É nesse momento que surge também uma das perspectivas críticas em Psicologia com base nas ideias da Psicologia histórico-cultural de Vygotsky (1896-1934), os estudos de Luria e Leontiev e tem como base o materialismo histórico e dialético.

Em 1945 Virginia Leone Bicudo, sobre a orientação de Donald Pierson, escreveu a primeira dissertação de mestrado sobre relações étnico-raciais dentro de uma instituição universitária brasileira no estado de São Paulo. E "em 1950, Dante Moreira Leite publica o artigo: Preconceito Racial e Patriotismo em Seis Livros Didáticos, no Boletim 03 de Psicologia, da Faculdade de Filosofia, Letras e Ciências Humanas da USP" (Santos, Schucman \& Martins, 2012, p.171).

A partir da década de 1990, os estudos sobre relações étnico-raciais se aprofundam nas questões sobre o branqueamento e branquitude, abrindo novas diretrizes de estudo no campo e trazendo alguns teóricos importantes como Maria Aparecida Bento, Jurandir Freire Costa, Edith Pizza e Iray Carone.

Fruto das ações e ou pressões do Movimento Negro Unificado (MNU), diferentes ações foram tomadas por organismos governamentais, um exemplo disso foi a Comissão de Direitos Humanos do Conselho Federal de Psicologia (CFP) criada em 7 de agosto de 1997, e as Comissões de Direitos Humanos dos Conselhos Regionais (CRPs) a partir de 1998, com destaque para o Conselho Regional de São Paulo que lançou duas publicações em parceria com o Centro de Estudos das Relações de Trabalho e Desigualdades (CEERT). Durante o Fórum Social Mundial, realizado em Porto Alegre, entre os dias 31 de janeiro e 4 de fevereiro de 2002, foi lançada, pela Comissão Nacional de Direitos Humanos do CFP, a campanha: "Preconceito Racial Humilha: Humilhação Social faz Sofrer". Como resultado desta campanha tem-se o estabelecimento de normas de atuação dos(as) Profissionais de Psicologia em relação ao preconceito e discriminação racial, a Resolução CFP Nº18/2002.

Neste mesmo ano, foi lançado o número 22.4 da Revista Psicologia: Ciência e Profissão que apresentou o tema "Pluralidade Étnica: um desafio à Psicologia Brasileira". Os avanços continuaram nas questões raciais em 2003, pois o Governo Federal estabeleceu a lei que incluiu o ensino da cultura africana nas escolas. “O presidente Luiz Inácio Lula da Silva sancionou a Lei n¹0.639, no dia 09/01/2003, que institui a obrigatoriedade da inclusão do ensino da História da África e da Cultura Afro-brasileira nos currículos (...) de ensino da educação básica". (Munanga, Gomes, 2006, p40.).

Nesse macro contexto, o Grupo de Trabalho Psicologia e Relações Raciais (GTPRR) do Conselho Regional de Psicologia da Bahia foi criado em janeiro de 2007, com a intenção de ser um instrumento de combate ao racismo no âmbito da Psicologia baiana, além de ser um espaço de formação para a categoria. Em 2008, foi lançada a primeira versão do Guia de Referências em Psicologia e Relações Raciais pelo Grupo de Trabalho Psicologia e Relações Raciais (GTPRR) do Conselho Regional de Psicologia da Bahia. Neste mesmo ano, o Conselho Regional de Psicologia de São Paulo realiza a publicação da série Cadernos Temáticos, o primeiro Caderno da série tem, como tema, a posição da Psicologia diante do Preconceito Racial.

Para colaborar no enfrentamento ao racismo em 2010 no I Encontro Nacional de psicólogas (os) negras (os) e pesquisadoras (es) das relações raciais e subjetividades (PSINEP) em São Paulo, foi criada a Articulação Nacional de Psicólogas (os) Negras (os) e Pesquisadoras e Subjetividade(es) - ANPSINEP.

Foi realizado, em maio de 2014 no Recife/PE, o II Encontro Nacional de Psicólogas (os) Negras (os) e Pesquisadoras (es) das Relações Raciais e Subjetividades (PSINEP). Demonstrando que a Psicologia, ao longo dos anos tem se dedicado cada 
vez mais as questões Ligadas à sociedade, buscando formas inovadoras e criativas para lidar com o sofrimento e a complexidade humana.

Outro importante marco é o lançamento das Referências Técnicas para a atuação de psicólogas no âmbito das Relações Raciais em 2017. Este documento foi elaborado pelo Conselho Federal de Psicologia, através do Centro de Referência Técnica em Psicologia e Políticas Públicas - CREPOP, com a finalidade de fornecer embasamento para que psicólogas/os em seus diversos campos de atuação possam reconhecer, refletir e criar estratégias de combate ao racismo (CFP, 2017).

Dando continuidade as propostas de intervenção a favor de um novo paradigma antirracista na Psicologia, a Liga Acadêmica de Relações Raciais (LARR) surge como uma outra proposta ético-política dentro das próprias configurações do que seriam as Ligas Acadêmicas tradicionais, assim veremos a seguir.

\section{As Ligas Acadêmicas no Brasil}

A tradição da construção de Ligas Acadêmicas em Saúde se originou no Brasil, segundo a Associação Brasileira de Ligas Acadêmicas em Medicina - ABLAM, em 1918, com a constituição da Liga de Combate à Sífilis na Faculdade de Medicina da Universidade de São Paulo. Essa forma de organização da produção do conhecimento se revitalizou em vários momentos da nossa história. Segundo Costa (2007), a Liga Brasileira de Higiene Mental - LBHM surge dez anos depois (1928 a 1934). Esta Liga, embora constituída com objetivos antagônicos ao propósito da LARR, possui um significado relevante para o presente relato, uma vez que a experiência de uma LARR se propõe um século depois, no início do século XXI com a possibilidade de ressignificar o sentido de uma Liga Acadêmica no âmbito da Psicologia.

No Brasil nos anos da ditadura militar, décadas de 1960 e 1970, a Faculdade de Medicina em São Paulo buscou revitalizar também sua tradição de Ligas Acadêmicas. E nesse contexto, houve questionamentos sobre a essência do ensino universitário, o direcionamento e a aplicabilidade dos avanços técnico-científicos.
A criação da Lei de Diretrizes e Bases da Educação Nacional (LDB) em 1996, que definiu o papel da educação superior, estimulou aos acadêmicos estabelecer relações com as realidades das comunidades nas quais fazem parte gerando novos conhecimentos e prestação de serviço para elas. Torres (2008) afirma que apenas a partir da constituição de 1988 estabeleceu-se o princípio da indissociabilidade entre ensino, pesquisa e extensão, para o papel das Ligas Acadêmicas em Saúde, fortalecendo uma nova forma de estimular a busca do conhecimento.

A concepção histórica dos fenômenos psicológicos permite que se pense o sujeito e o mundo em constante movimento. Entretanto, a ciência psicológica ainda se constitui a partir da noção de natureza humana, em que o ser humano é visto como uma construção de si próprio. Assim, todas as oportunidades de se repensar o nosso conhecimento são bem vindas e necessárias no ambiente acadêmico. Como nos mostra Bock (2004), é preciso superar o controle, a categorização e a diferenciação, compreendidas como processos "naturais" e transformar esse modo de produção do conhecimento e de olhar sobre as relações interpessoais em um compromisso da Psicologia para com as necessidades concretas da população e na construção de projetos sociais.

As Ligas Acadêmicas não são frequentes no âmbito da psicologia.

Para um melhor entendimento sobre o assunto, será abordada como se deu a criação da Liga, suas atividades desenvolvidas e em que momento a mesma se encontra atualmente.

\section{Método}

Este artigo caracteriza-se como um estudo de abordagem qualitativa e descritiva. O procedimento utilizado foi o relato de experiência a partir das descrições das autoras/es que vivenciaram os dois primeiros anos do percurso da Liga Acadêmica de Relações Raciais, iniciado em 2016 no curso de psicologia da instituição de ensino EBMSP. 
O relato de experiência é entendido como um estudo de caráter qualitativo, que abrange uma característica descritiva, mas não circunscrita a ela, podendo abarcar muitas opções epistêmicas e metodológicas na interpretação dos fenômenos no processo de construção do conhecimento (Daltro \& Faria, 2019).

De acordo com Minayo (2009), a abordagem qualitativa permite responder questões singulares da realidade ao se aprofundar no universo dos significados das ações e das relações humanas com os seus semelhantes e com o mundo. Trabalhar com o universo dos significados é interpretar a realidade dos fenômenos humanos constituídos socialmente como as relações, os valores, as crenças e as atitudes que não cabem às explicações mensuráveis e quantificadas.

A pesquisa descritiva segundo Gil (2008) tem como objetivo descrever as características do objeto de estudo. Tem como sua especificidade a utilização de técnicas padronizadas que visam organizar com exatidão os detalhes e as informações dos fenômenos observados.

As técnicas que compõem este relato foram os registros das reuniões e das reflexões coletivas suscitadas a partir das leituras de artigos científicos e livros, cine debates, participações em diversos eventos científicos e sociais, rodas de conversas com convidados sendo estes profissionais de psicologia em diferentes áreas de atuação. Esses métodos utilizados contribuíram para uma sistematização da vivência de discentes, docentes e profissionais na construção de um espaço propulsor de conhecimento para além dos limites territoriais da faculdade.

\section{Descrição do Processo de Construção da Liga de Relações Raciais}

Assim como dito anteriormente, é possível identificar em maior número Ligas acadêmicas relacionadas ao curso de medicina. A EBMSP não foge à regra, visto que encontram-se 34 Ligas do curso de Medicina e 12 Ligas dos demais cursos oferecidos pela instituição, totalizando a existência de 46 Ligas Acadêmicas na atualidade. Dentre elas estão duas Ligas acadêmicas do curso de Psicologia, com as temáticas de Sexualidade e Gênero (LASG) e de Relações Raciais (LARR). Magalhães, Rechtman e Barreto (2015) afirmam que o número crescente de Ligas acadêmicas em psicologia pode ser um caminho para aprofundar discussões em temáticas pouco discutidas ou invisibilizadas na graduação.

Posto isso, no dia 02 de fevereiro de 2016 foi fundada a Liga Acadêmica de Relações Raciais (LARR) na EBMSP, projeto esse elaborado/desenvolvido por dois discentes e três Psicólogas egressas da mesma instituição. A Liga possui como objetivos desenvolver a responsabilidade e o compromisso social dos membros com as questões Étnico-raciais na atualidade. $\mathrm{E}$ promover a participação em seminários, cursos, congressos e debates que abordem o tema, bem como produzir trabalhos científicos para contribuir com a construção do conhecimento cultural e identitário no campo da educação em diálogo com os temas: cultura, raça, cor e etnia.

O projeto da Liga foi idealizado durante um semestre, no qual foram realizadas reuniões para o amadurecimento do projeto, discussões sobre a relevância da Liga para a formação dos graduandos em Psicologia e sua adequação às atividades complementares do currículo do curso de Psicologia, e a construção do seu estatuto respeitando esses itens elencados, tendo como base teórica a Psicologia Sócio-Histórica. E a metodologia de trabalho desenvolvida teve como base o seu estatuto que define as normas de atuação e intervenção de acordo com as regras instituídas pela EBMSP.

A LARR é composta por quinze (15) alunas de Psicologia, das quais duas (2) formam a Diretoria, três (3) são Membros Fundadores e dez (10) são membros ativos. $O$ ingresso das/os membros ativas/os aconteceu através de seleção por avaliação escrita e entrevista no processo inclusivo (foi escolhido este nome com a proposta de incluir as pessoas já no início do processo) a serem realizados pelas/os membros da Liga. As pessoas que podem participar da seleção para a LARR são alunas/os da EBMSP que estejam cursando do primeiro ao último semestre (período), assim como Ex-Alunas/os da instituição. De acordo com o estatuto, todas as atividades feitas são supervisionadas por dois professores tutores, uma psicóloga e um sociólogo, que se dedicam ao estudo das questões étnico-raciais.

A diretoria conta com 1(um) Presidente; 1(um) VicePresidente; 1(um) Coordenador Administrativo e Financeiro; 2 (duas) coordenadoras de Mídias. Com esta estrutura, as atividades da LARR iniciaram em 
março de 2016, realizando o total de 13 reuniões (todas as terças-feiras das 14 às 16 horas) dentro da EBMSP no bairro de Brotas e uma sessão aberta para acadêmicos da EBMSP e de outras instituições de ensino superior realizada dentro da instituição. Utilizouse a Revisão de Literatura (leituras de artigos científicos e livros) e a Análise de Filmes como metodologias para os encontros semanais.

A partir de um cronograma construído dentro das primeiras reuniões, foram estudadas e discutidas as algumas temáticas. Através de artigos de autores brasileiros da atualidade e filmes. Os filmes utilizados foram: (The Help), Histórias Cruzadas em português, do diretor Tate Taylor que adaptou o roteiro do filme baseado no romance de Kathryn Stockett; Bicho de Sete cabeças, da diretora Laís Bodanzky, filme baseado no livro autobiográfico "Canto dos Malditos" de Austregésilo Bueno.

De acordo com Bock (2004), somos constituídos psiquicamente a partir da realidade que nos é apresentada socialmente. Se socialmente nos relacionamos com um mundo hierarquizado, que discrimina, separa e elege padrões a serem alcançados e consumidos, logo, a nossa estrutura psíquica responderá na mesma medida, sofrendo e/ou fazendo sofrer. Assim, todas as atividades promovidas foram estímulos para reflexões sobre a consciência de si mesmo e análise da realidade concreta que permeia a sociedade soteropolitana e brasileira como um todo.

A LARR foi convidada a participar de alguns eventos como o Café Científico; da Semana de Psicologia; da XVI Mostra Científica e Cultural da Escola Bahiana de Medicina; do III Fórum do Centro de Atenção às Juventudes (CAJU); dos quatro Colóquios de Saúde Mental da População Negra. Eventos estes realizados pela própria instituição de ensino que a Liga está inserida, onde foi possível facilitar alguns debates através de dinâmicas e rodas de conversa dentro dos espaços citados.

\section{Resultados}

No final do ano de 2016, foi realizada a última reunião do semestre com todos os membros da Liga, na qual foi efetivado um balanço anual sobre os conhecimentos adquiridos dentro das Relações Étnico-raciais e Psicologia, avaliando as dificuldades vivenciadas por alguns e pelo grupo de maneira geral. Ao final do primeiro semestre de funcionamento da Liga, foi possível perceber que ainda existia uma grande lacuna no debate das relações Étnicos Raciais neste ambiente acadêmico mesmo com a existência do grupo de pesquisa: Psicologia, Diversidade e Saúde que era o único dentro do curso que trabalhava e estudava com questões Ligadas diretamente ao tema da Liga.

Em fevereiro de 2017, ocorreram reuniões da Diretoria e Membros Fundadores para a organização do Calendário semestral e do Processo inclusivo abrindo vagas para novas/os membros. As atividades se iniciaram no mês de março realizando 7 reuniões, das 15 programadas, semanalmente (todas as sextas-feiras das 18 às 20 horas) no prédio da EBMSP.

Magalhães, Rechtman e Barreto (2015) percebem a Liga acadêmica como um impulsionador da vida estudantil, deslocando o discente da sala de aula para ocupar outros espaços produzindo e compartilhando conhecimentos com autonomia e disposição para construir pontes dentro da própria academia e fora com e na sociedade. Assim, a metodologia utilizada nos encontros continuou sendo uma Revisão de Literatura (um encontro fechado só para os membros para discussão de textos) semanalmente e um encontro aberto para toda a comunidade de EBMSP (uma vez por mês) e a Análise de filmes/curtas com a temática de relações étnica raciais. Foram debatidos alguns temas como: Feminismo e Estética Negra, o Genocídio da População Negra, a Necropolítica, enquanto projeto do Capitalismo.

Os calendários dos semestres subsequentes foram confeccionados nas reuniões, nas quais todos podiam participar de forma democrática sugerindo e escolhendo temas a serem estudados e filmes/séries a serem exibidos nas datas selecionadas. Além das participações nos eventos da EBMSP e parcerias estabelecidas com outras Instituições e Sociedade Civil. Periodicamente, foram presenciados momentos de avaliações da dinâmica do coletivo, sugeridas algumas reconstruções de rotas e reflexões sobre a necessidade de envolvimento do maior número possível de participantes, bem como na necessidade de melhor distribuição de responsabilidades. 
Portanto considera-se a construção da LARR uma experiência que proporcionou movimentos importantes dentro da instituição a qual pertence, pois além de cumprir os objetos propostos em pouco tempo, ampliou o diálogo entre as/os professores e estudantes do curso, em uma instituição privada cujo o conjunto do corpo docente e discente, em sua ampla maioria, são fenotipicamente brancos e necessitam refletir sobre o papel da formação da sociedade brasileira e o compromisso social da Psicologia.

Vale ressaltar também os impactos que as políticas públicas de equidade racial tiveram durante o processo de consolidação da Liga. A maioria das/os alunas/ os negras/os da EBMSP, bem como as/os membros da LARR, eram usuárias/os de políticas de financiamento estudantil, o que além de demarcar a racialização dessas políticas, demonstram sua efetividade. Consequentemente, após a PEC $n^{\circ} 241 / 55$, também conhecida como "PEC do Teto", houve uma redução de investimentos na área de educação, saúde entre outros, por parte do Governo Federal, resultando numa menor inserção de jovens no ensino superior através dessas políticas, culminando na redução da juventude negra nesses espaços

Por isso, nos anos seguintes ao estabelecimento da PEC do Teto, percebemos uma redução drástica no número de novos Ligantes, bem como a inserção reduzida de negros na EBMSP, o que acabou estratificando a formatação da Liga em seus últimos anos. Também, com a formatura de seus membros mais antigos, a Liga passou por um processo de esvaziamento, o que logo alertou os demais membros para a necessidade de uma reformulação em suas diretrizes.

\section{Considerações finais}

A experiência descrita na LARR demonstrou que ela tem em suas bases a preocupação com a formação e preparação das/os estudantes em atuar com o sofrimento psíquico que o Racismo pode causar.

Com o transcorrer do tempo foi possível perceber uma maior compreensão sobre questões que envolvem as Relações Étnico-Raciais e suas nuances no cotidiano acadêmico. A LARR se coloca, também, enquanto um importante instrumento de formação para se fazer pensar o papel da Psicologia e da(o) Psicóloga(o) frente às questões Raciais que atravessam a sociedade.
Notou-se que há uma falta generalizada não apenas no curso de Psicologia, mas também em outros cursos da instituição, pelas demandas que chegaram até a Liga e a seus membros.

Restou o aprendizado da importância de se trabaIhar para modificar a realidade do cotidiano atual. Portanto, essa Liga se mostrou como espaço para mudanças concretas através das práticas do exercício de cidadania e compromisso social que pautam o fazer de uma categoria preocupada em assegurar os Direitos Humanos e a prática da Ética em todos os lugares.

Hoje a Liga se encontra formada por ex-alunas(os) e docentes da instituição, determinadas(os) a reconstruir esse espaço que Ihes é tão caro. Pensando a importância da Liga Acadêmica de Relações Raciais como um espaço nômade, determinado a não só produzir academicamente, mas também como um lugar de acolhimento e aquilombamento por parte das pessoas que ela compõe. Essa também se configura como um campo político e de resistência frente a causar rupturas aos modelos hegemônicos de ensino, propondo outras metodologias de discussão para além das convencionais. Atualmente, devido à pandemia, a Liga vem se repensando para o formato on-line, levando em conta as impossibilidades provocadas pelo novo Coronavírus, mas se propondo a construir incessantemente uma outra Psicologia, política, crítica e antirracista.

\section{Contribuições dos autores}

Da Purificação TS participou de todas as etapas da pesquisa sendo responsável pela concepção e escrita do artigo. Khouri JGR, Santos JDN participaram da interpretação dos dados, elaboração do desenho e a escrita final do artigo. Galrão HAS participou da elaboração final do texto. Castelar M participou da orientação para a concepção e na elaboração final do artigo. Todos/as os/as autores/as aprovaram a versão final do artigo.

\section{Conflitos de interesses}

Nenhum conflito financeiro, legal ou político envolvendo terceiros (governo, empresas e fundações privadas, etc.) foi declarado para nenhum aspecto do trabalho submetido (incluindo, mas não se limitando a subvenções e financiamentos, participação em conselho consultivo, desenho de estudo, preparação de manuscrito, análise estatística, etc.). 


\section{Referências}

Alberti, V., \& Pereira, A.A. (2005). Movimento negro e democracia racial no Brasil: entrevistas com lideranças do movimento negro. CPDOC.

Almeida, S.L. (2019). O que é racismo estrutural. Pólen.

Araújo, J.Z. (2006). A força de um desejo: a persistência da branquitude como padrão estético audiovisual. Revista USP (69), 72-79. https://doi.org/10.11606/issn.2316-9036. v0i69p72-79

Associação Brasileira de Ligas Acadêmicas em Medicina (2020). Diretrizes Nacionais em Ligas Acadêmicas de Medicina. https://web.archive.org/web/20130608001140if/http:// www.ablam.org.br/institucional.html

Bacelar, J. (2001). A hierarquia das raças: negros e brancos em Salvador. Pallas.

Bock, A.M.B. (2004). A perspectiva histórica da subjetividade: uma exigência para a psicologia atual. Psicologia para América Latina, (1). http://pepsic.bvsalud.org/scielo.php?script=sci_ arttext\&pid=S1870-350X2004000100002\&Ing=pt\&tIng=pt

Cogo, D., \& Machado, S. (2010). Redes de negritude: usos das tecnologias e cidadania comunicativas de afro-brasileiros. Anais do Congresso Brasileiro de Ciências da Comunicação (Intercom), Caxias do Sul, 23, (1), 1-16. http://www. intercom.org.br/papers/nacionais/2010/resumos/R5-16501.pdf

Conselho Federal de Psicologia (2002). Norma que combate preconceito e discriminação racial faz 15 anos. https://site. cfp.org.br/tag/resolucao-cfp-18-2002/

Costa, J.F. (2007). História da Psiquiatria no Brasil: um corte ideológico (5a ed.) Garamond.

Daltro, M.R., \& Faria, A.A. (2019). Relato de experiência: uma narrativa científica na pós-modernidade. Psicologia clínica e Psicanálise, 19(1), 223-237. https://www.e-publicacoes. uerj.br/index.php/revispsi/article/view/43015/29664

Domingues, P. J. (2005). O mito da democracia racial e a mestiçagem no Brasil (1889-1930). Diálogos Latino americanos, (10), 115-131. https://www.redalyc.org/ pdf/162/16201007.pdf

França, E.J., Rocha, R.V.S., \& Castelar, M. (2015). Grupo de Trabalho Psicologia e Relações Raciais do CRP03: Formação Crítica e Engajamento Político. Revista Brasileira de Psicologia, 02(núm. esp.), 28-38. https://docplayer.com.br/13582478Grupo-de-trabalho-psicologia-e-relacoes-raciais-do-crp03formacao-critica-e-engajamento-politico.html

Gil, A.C. (2008). Como elaborar projetos de pesquisa (4a ed.). Atlas.

Hur, D. H. (2019). Psicologia, Política e Esquizoanalise (2a ed). Alínea
Magalhães, E.P., Rechtman, R., \& Barreto, V. (2015). A Liga acadêmica como ferramenta da formação em Psicologia: experiência da LAPES. Psicologia Escolar e Educacional, 19(1), 135-141. https://doi.org/10.1590/21753539/2015/0191813

Masiero, A.L. (2005). A Psicologia Racial no Brasil (1918-1929). Estudos de Psicologia, 10(2), 199-206. https://doi. org/10.1590/S1413-294X2005000200006

Minayo, M.C.S. Pesquisa social (28a ed.): teorias método e criatividade. Vozes.

Miranda, C.A.M. (2007). O silêncio como forma de racismo: a ausência de negros na publicidade brasileira. InterSciencePlace, 1(2), 1-11. http://interscienceplace.org/ isp/index.php/isp/article/view/14

Munanga, K., \& Gomes, L.N. (2006). O Negro no Brasil de hoje. Global.

Nascimento, A.J.F. (2019). O Genocídio do Negro Brasileiro: Processo de um Racismo Mascarado. Perspectivas

Nunes, S.S. (2006). Racismo no Brasil: tentativas de disfarce de uma violência explícita. Psicologia USP, 17(1), 89-98. https:// doi.org/10.1590/S0103-65642006000100007

Oliveira, I. M., \& Silva, L. A. P. (2007). Imprensa Negra Online: o racismo na pauta de todos os dias. Afropress. http://www. afropress.com/post.asp?id=13131

Oliveira, V., \& Ronsini, V. M. (2007). Ativismo negro: afirmação étnica e a reprodução do racismo na mídia. VIII Congresso Brasileiro de Ciências da Comunicação da Região Sul, Passo Fundo, RS, Brasil. http://www.intercom.org.br/papers/ regionais/sul2007/resumos/R0092-1.pdf

Pereira, G. M., Santos, J. K. C., \& Costa, L. A. (2001). Dano moral nos atos de racismo. Djumbay.

Santos, A. O., Schucman, L.V., \& Martins, H.V. (2012). Breve histórico do pensamento psicológico brasileiro sobre relações étnico-raciais. Psicologia: Ciência e Profissão, 32(spe), 166-175. https://doi.org/10.1590/S1414$\underline{98932012000500012}$

Santos, G. A. (2002). A Invenção do Ser Negro: um percurso das ideias que naturalizaram a inferioridade dos negros. Educ.

Schucman, L.V. (2010). Racismo e antirracismo: a categoria raça em questão. Revista Psicologia Política, 10(19), 41-55. http://pepsic.bvsalud.org/scielo.php?script=sci arttext\&pid=S1519-549X2010000100005\&lng=pt\&tlng=pt

Torres, A.R., Oliveira, G.M., Yamamoto, F.M., \& Lima, M.C.P. (2008). Ligas Acadêmicas e formação médica: contribuições e desafios. Interface - Comunicação, Saúde, Educação, 12(27), 713-720. https://doi.org/10.1590/S141432832008000400003 